\title{
Design of Access Control System for Hangul document System
}

Seung Ju Jang

Dong-Eui University, 614-714 Busan

Republic of Korea

sjjang@deu.ac.kr

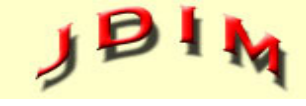

Journal of Digital Information Management

\begin{abstract}
In this paper, we design an access control system that enables a specific user to use a document in a Hangul document system. The system structure designed in this paper is to analyze the Hangul document structure and modify the Hangul document head information. By modifying the function of a specific field of Hangul document head information, a user who does not have data on the transformed information will not be able to open and view the document. In this way, it can control the access to important Hangul documents. In this paper, we actually implemented what we design and performed experiments. Experimental results show that the access control system operates normally.
\end{abstract}

\section{Subject Categories and Descriptors}

[I.7.1 Document and Text Editing]; Document management: [D.4.6 Security and Protection]; Access controls: [H.2 Database Managment]; Security, integrity, and protection

\section{General Terms}

Document Protection, Security and Access Control, Korean Document Management System

Keywords: Hangul Document System, Access Control, Authentication User, Hangul Document Structure

Received: 11 March 2017, Revised 27 April 2017, Accepted 3 May 2017

DOI: $10.6025 /$ jdim/2017/15/4/170-178

\section{Introduction}

The National Intelligence Service recently published interesting data. It said that according to the survey of 500 companies, most of the surveyed companies have been poorly managing internal documents, which has been an impediment to industrial competitiveness. According to the report, 27 percent of the 500 companies were affected by confidential data leaks, and more than half (25.6 percent) of companies did not have regulations or guidelines for security management. In addition, $64.5 \%$ of the employees have never received security education, and the company showed no protection against leakage of important confidential data.

Recently, the digitalization and electronic transaction have spread in the industry. They have a great deal of dysfunctional role as well as a purely functional role in the business operation. Replacement of paper documents is accelerating with the activation of electronic records. As the use of electronic documents increases, document security becomes more important.

It estimates that domestic companies and financial institutions spend more than KRW 1 trillion a year on distribution and storage of various papers or documents recently. And it seems that it is difficult to use the accumulated documents for searching reference. These figures are merely the cost of document distribution and management. The security problem with electronic documents is that they have to pay a lot more cost than this.

In the case of an individual or a corporation, the use of the encryption/decryption technology is often to manage important electronic documents [1, 2]. When it comes to what it means to secure these electronic documents, it is easy to say that it permits only authorized persons to store, view, edit, and print electronic documents. In other 


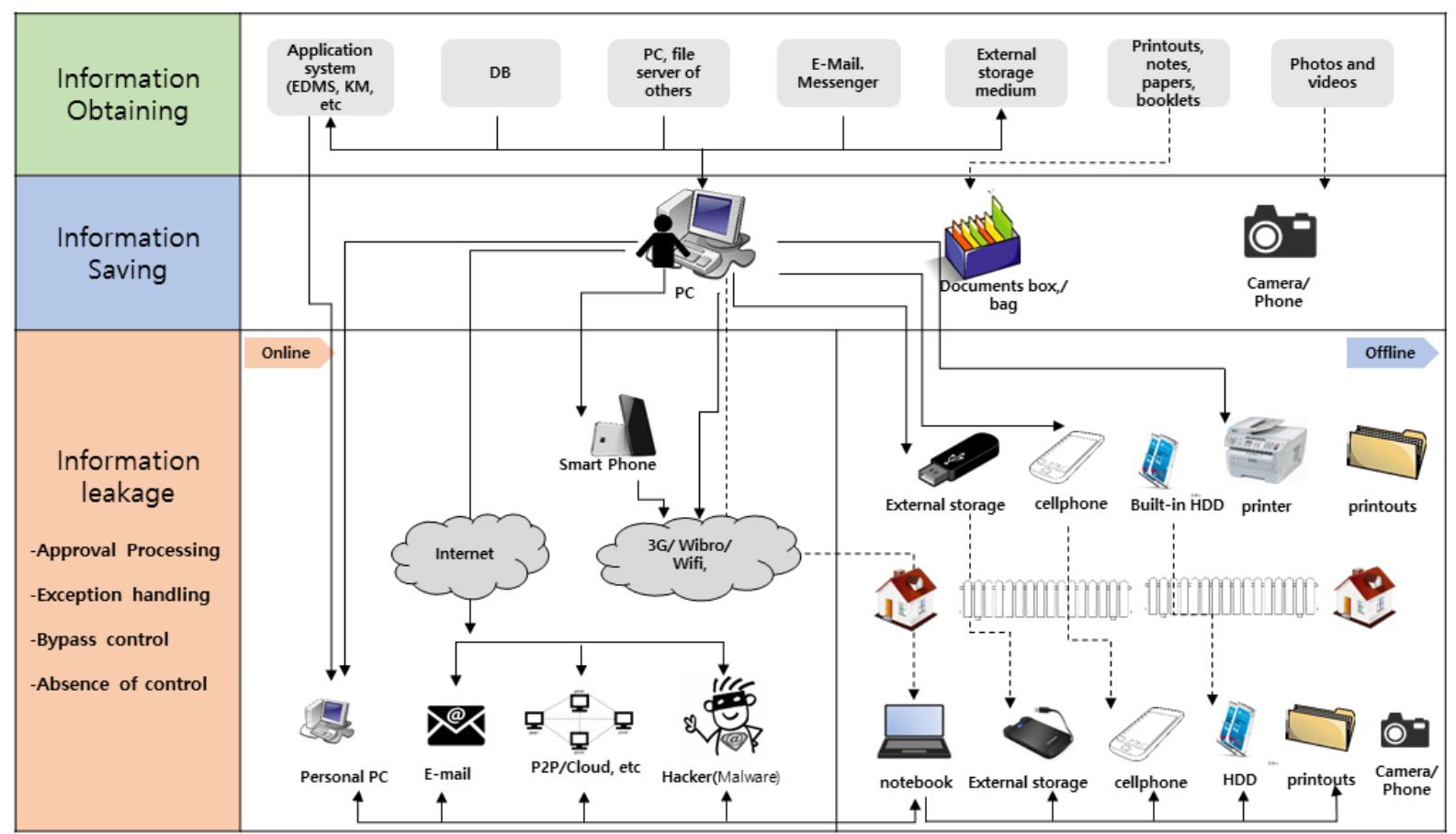

Figure 1. Various distribution channels of electronic documents

words, it is to block unauthorized activities. Furthermore, it can be considered to include prevention of straying and modulation of electronic documents $[3,4,5]$. However, because there are so many different kinds of electronic documents and distribution channels, it is not easy to block completely security threats from all of these.

Figure 1 shows the various distribution channels of electronic documents. As such, electronic documents and files are being distributed and delivered in various ways. Therefore, electronic documents and files are vulnerable to security.

Security is not just to stop like a barrier, but to use safely for a legitimate user. In this process, a vulnerability, ie, a hole (security hole), which is for not only legitimate users but also for unauthorized users, occurs together $[6,7]$.

In Korea, most of these electronic documents use 'Hangul' documents. Therefore, the security of 'Hangul' documents is getting more important. In this paper, we design a control system that is only for users who have security access rights to the Hangul documents (files).

Hangul, a Korean text editor, takes the Hangul Word Processor format. Therefore, in the case of a "Hangul" file, the file extension takes the form "hwp". The Korean text editor is also called "Hanword". This paper designs access control system for Hanword document.

Chapter 2 describes the related research, Chapter 3 describes the contents of the design of the access control system for the Hangul file, Chapter 4 explains the experiment and the result of the designed system, and Chapter 5 describes conclusions.

\section{Related Studies}

The use of electronic documents has been growing rapidly in recent years. The security problem of using these electronic documents is also becoming important. There are various studies on security systems related to electronic documents.

The encrypted document has the advantage of being able to protect it from external leakage. On the other hand, the disadvantage is that there are many obstacles due to the collision between programs because the program supports a variety of document. It should differentiate the permission according to the importance of electronic documents and the users. In addition, you have to turn off security whenever sending to a user who does not have permission. At this time, there is a complication and an inconvenience in use such as the acquisition of payment of a top-ranking person.

Many people do not keep electronic documents just on their PCs. It can be delivered to someone via e-mail, messenger, or web hard drive, or stored on a removable storage medium such as a smartphone, CD, USB, etc. and output to a printer. DLP (Data Loss Prevention) is a security control method that blocks or permits various paths from my PC to the outside and records the contents of the data in a log for tracking an accident. This can allow or block'online path', such as e-mail, messenger, web hard drive, P2P, etc. 'off line path', such as CD • DVD • USB • smart phone, etc. and the output of printer and fax. Not all paths can be blocked, but some paths such as mail and output is allowed to perform tasks. In addition, there is a weakness that it is not possible to retrieve an electronic document that has already gone out, although it can be traced. 


\begin{tabular}{|c|c|c|c|c|c|c|c|c|}
\hline \multicolumn{2}{|l|}{ Division } & Counter measures & Contents & \multicolumn{5}{|c|}{ Security Solutions } \\
\hline \multirow{3}{*}{$\begin{array}{l}\text { (1) Information } \\
\text { Acquisition }\end{array}$} & \multirow{2}{*}{ Applications } & $\begin{array}{l}\text { Authorization } \\
\text { Reorganization }\end{array}$ & $\begin{array}{l}\text { - Classification of infor- } \\
\text { mation and users } \\
\text { - Apply only the infor- } \\
\text { mation that is absolutely } \\
\text { necessary for business } \\
\text { according to the princi- } \\
\text { ple of least privilege }\end{array}$ & \multicolumn{3}{|c|}{ EAM/IAM } & & \multirow{10}{*}{$\begin{array}{l}\text { Desktop } \\
\text { Virtualiza } \\
\text {-tion } \\
\text { (SBC) }\end{array}$} \\
\hline & & Server DRM apply & $\begin{array}{l}\text { - Control of files } \\
\text { downloaded to PC } \\
\text { • Encryption, number of } \\
\text { open/period/output limit, } \\
\text { logging history, etc }\end{array}$ & \multicolumn{4}{|c|}{ DRM (Document security) } & \\
\hline & DB & $\begin{array}{l}\text { Access control and } \\
\text { monitoring }\end{array}$ & $\begin{array}{l}\text { - Enhanced access con- } \\
\text { trol and access history } \\
\text { auditing }\end{array}$ & \multicolumn{4}{|l|}{$\mathrm{DB}$} & \\
\hline \multirow{6}{*}{$\begin{array}{l}\text { (2) Online } \\
\text { outflow }\end{array}$} & \multirow{2}{*}{$\begin{array}{l}\text { Transmitting } \\
\text { from the down- } \\
\text { town }\end{array}$} & Block harmful sites & $\begin{array}{l}\text { - Block access to infor- } \\
\text { mation leakage sites } \\
\text { such as Web hard, P2P }\end{array}$ & \multicolumn{3}{|c|}{ Block harmful sites } & & \\
\hline & & $\begin{array}{l}\text { Outbound transmission } \\
\text { monitoring }\end{array}$ & $\begin{array}{l}\text { - Mail/bulletin board/ } \\
\text { messenger/web hard/ } \\
\text { FTP transmission } \\
\text { history logging }\end{array}$ & \multicolumn{3}{|c|}{$\begin{array}{l}\text { External transfer } \\
\text { monitoring/ DLP }\end{array}$} & & \\
\hline & \multirow{3}{*}{$\begin{array}{l}\text { Transmitting } \\
\text { from the } \\
\text { suburbs }\end{array}$} & VPN control & $\begin{array}{l}\text { - Enhanced VPN account } \\
\text { control/authentication } \\
\text { and virtualization of } \\
\text { access environment }\end{array}$ & \multicolumn{3}{|l|}{ SBC } & $\mathrm{P}$ & \\
\hline & & $\begin{array}{l}\text { Transmission monitor- } \\
\text { ing/Interception }\end{array}$ & $\begin{array}{l}\text { - External transmission } \\
\text { history logging such as } \\
\text { mail bulletin board/blog } \\
\text { • Block the execution of } \\
\text { dangerous programs } \\
\text { such as P2P and } \\
\text { messenger }\end{array}$ & \multirow[t]{2}{*}{$\begin{array}{l}\mathrm{PC} \\
\text { Security }\end{array}$} & \multirow{4}{*}{\multicolumn{2}{|c|}{\begin{tabular}{l|l} 
NA & access \\
C & control \\
- Equ ip - \\
ment \\
i m p or t \\
export \\
control
\end{tabular}}} & $\begin{array}{l}C \\
D \\
R \\
M\end{array}$ & \\
\hline & & Export control & $\begin{array}{l}\text { - Control of equipment } \\
\text { export, such as } \\
\text { notebooks }\end{array}$ & & & & & \\
\hline & $\begin{array}{l}\text { External storage } \\
\text { media }\end{array}$ & $\begin{array}{l}\text { Media blocking and } \\
\text { logging }\end{array}$ & $\begin{array}{l}\text { - Blocking and logging } \\
\text { external storage media } \\
\text { such as USB/FDD/ } \\
\text { CD-RW }\end{array}$ & $\begin{array}{l}\cdot \text { PC Secu } \\
\text {-rity•DLP } \\
\cdot \text { Security } \\
\text { USB }\end{array}$ & & & & \\
\hline \multirow{2}{*}{$\begin{array}{l}\text { (3) Online } \\
\text { outflow }\end{array}$} & Built-in HDD & HDD Encryption/Seal & $\begin{array}{l}\text { • HDD encryption or } \\
\text { Seal Sticker }\end{array}$ & $\begin{array}{l}\text { HDD encryp } \\
\text {-tion }\end{array}$ & & & & \\
\hline & output & $\begin{array}{l}\text { Watermarking and } \\
\text { logging }\end{array}$ & $\begin{array}{l}\text { - Force insert outputting } \\
\text { information and output } \\
\text { history logging }\end{array}$ & \multicolumn{5}{|c|}{$\begin{array}{l}\text { - Output security } \\
\text { - OAA device security }\end{array}$} \\
\hline \multirow{2}{*}{\multicolumn{2}{|c|}{$\begin{array}{l}\text { Integrated analysis } \\
\text { management }\end{array}$}} & $\begin{array}{l}\text { Evidence collection and } \\
\text { analysis }\end{array}$ & $\begin{array}{l}\text { - Investigate the incident } \\
\text { and obtain legal evidence }\end{array}$ & \multicolumn{5}{|c|}{ Digital Forensic } \\
\hline & & $\begin{array}{l}\text { Integrated security } \\
\text { monitoring }\end{array}$ & $\begin{array}{l}\text { - Integrated analysis, } \\
\text { information leak } \\
\text { detection, blacklist } \\
\text { management, etc }\end{array}$ & \multicolumn{5}{|c|}{$\begin{array}{l}\text { Integrated information leakage } \\
\text { monitoring system }\end{array}$} \\
\hline
\end{tabular}

Table 1. Electronic document security solution 


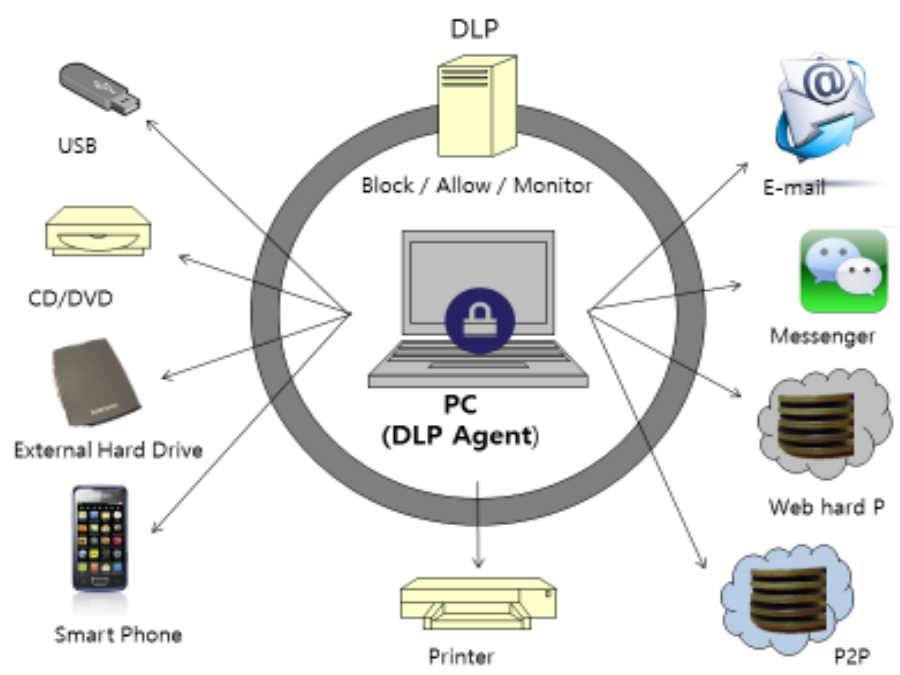

Figure 2. Electronic document distribution system

\section{System Structure of Hangul document}

The system structure of Hangul document is as follows. Hangul files are compound files. Hangul 2014 supports lots of file formats. Looking at the extensions, there are also unfamiliar extensions as well as familiar extensions like hwp, hwpx, hml, doc and docx. Among them, the object related to document access control is targeted to hwp which is a traditional Hangul extension. We take a quick look at the hwp file format. The hwp file has the following structure.
The first four to sixteen bytes of a file are file header data structures for identifying each file. The 4 bytes of the Hangul file we know are $\backslash x \mathrm{~d} 0 \backslash \mathrm{xcf} \backslash \mathrm{x} 11 \backslash \mathrm{xe} 0$ (DOCFILE). This is consistent with OLE's file header. Before looking over Hangul file, we should look into OLE structure.

\subsection{Object Linking \& Embedding (OLE) Structure} As the name implies, it is a data structure used to insert (or link) any object (picture, video, flash, etc.). The OLE structure itself is similar to the file system. The OLE structure looks like this:

\begin{tabular}{|c|}
\hline HEADER \\
\hline SECTOR 0 \\
\hline SECTOR 1 \\
\hline SECTOR 2 \\
\hline SECTOR 3 \\
\hline SECTOR 4 \\
\hline SECTOR 5 \\
\hline SECTOR 6 \\
\hline
\end{tabular}

Figure 3. Structure of Hangul file

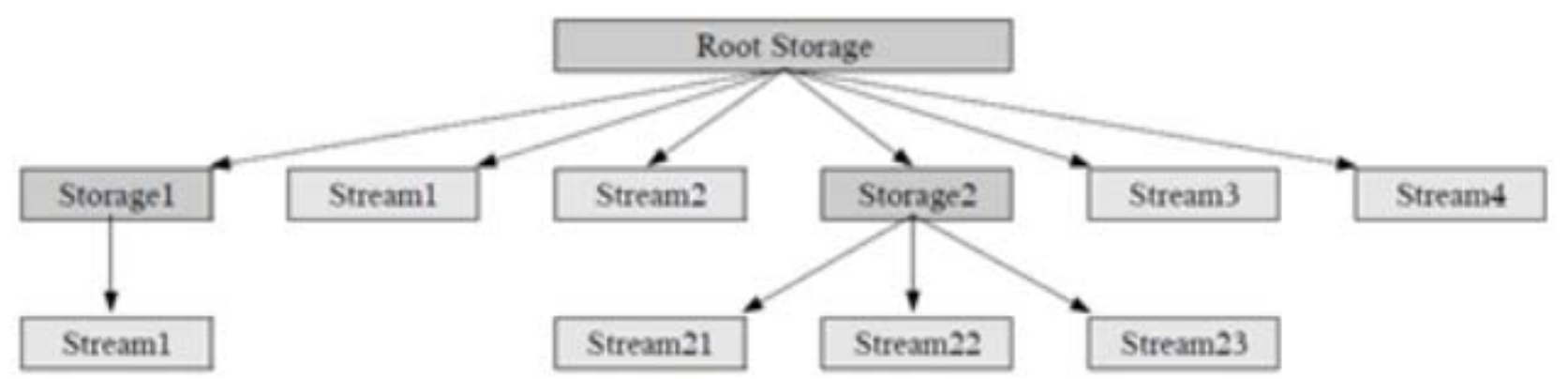

Figure 4. OLE structure of Hangul file 


\begin{tabular}{|c|c|c|c|c|}
\hline Explaration & Distinguisted name & $\begin{array}{l}\text { Length } \\
\text { (bytes) }\end{array}$ & $\begin{array}{l}\text { Record } \\
\text { structure }\end{array}$ & $\begin{array}{l}\text { Compression } \\
\text { / Encryption }\end{array}$ \\
\hline $\begin{array}{l}\text { File Recognition } \\
\text { In fomation }\end{array}$ & Elfleheader & feed & & \\
\hline $\begin{array}{l}\text { Document } \\
\text { In fomation }\end{array}$ & EDoclnó & feed & $\sqrt{ }$ & $\sqrt{ }$ \\
\hline Nain Text & 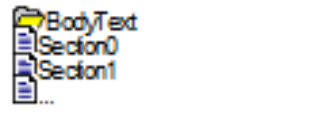 & variable & $\sqrt{ }$ & $\sqrt{ }$ \\
\hline $\begin{array}{l}\text { Document } \\
\text { Surmary }\end{array}$ & GoOsHupSummanh fomation & fed & & \\
\hline Brandata & 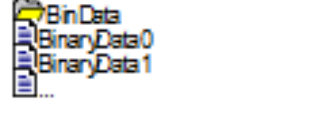 & variable & & $\sqrt{ }$ \\
\hline Prevew Text & EPrvText & fed & & \\
\hline Prevew Inage & EPrvmage & variable & & \\
\hline Docunent Options & 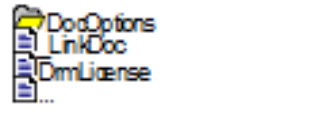 & variable & & \\
\hline Scipt & $\begin{array}{l}\text { EDefaut Scriot } \\
\text { ElJScriptVerson } \\
\text { E... }\end{array}$ & variable & & \\
\hline XML Template & $\begin{array}{l}\text { Scheng } \\
\text { Elinstence } \\
\text { E... }\end{array}$ & variable & & \\
\hline $\begin{array}{l}\text { Document History } \\
\text { Managenent }\end{array}$ & 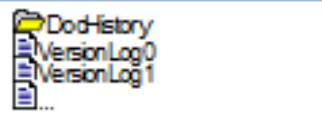 & variable & $\sqrt{ }$ & $\sqrt{ }$ \\
\hline
\end{tabular}

Figure 5. Hangul document structure

It can be classified into three categories.

\section{- RootStroage}

- Strorage: Classify streams

- Stream: Physical files (images, data, etc.)

Using the HwpScan2 analysis tool, the OLE structure above is as follows. It is classified, storage and stream according to the tree form of OLE structure. The document file of Hangul has the following structure in general. Since it has a compound file structure, it internally has a name for distinguishing between storage and a stream.

One stream stores data in the usual binary or record structure, and is compressed / encrypted according to the stream.

$\bullet$ Storage 目Stream

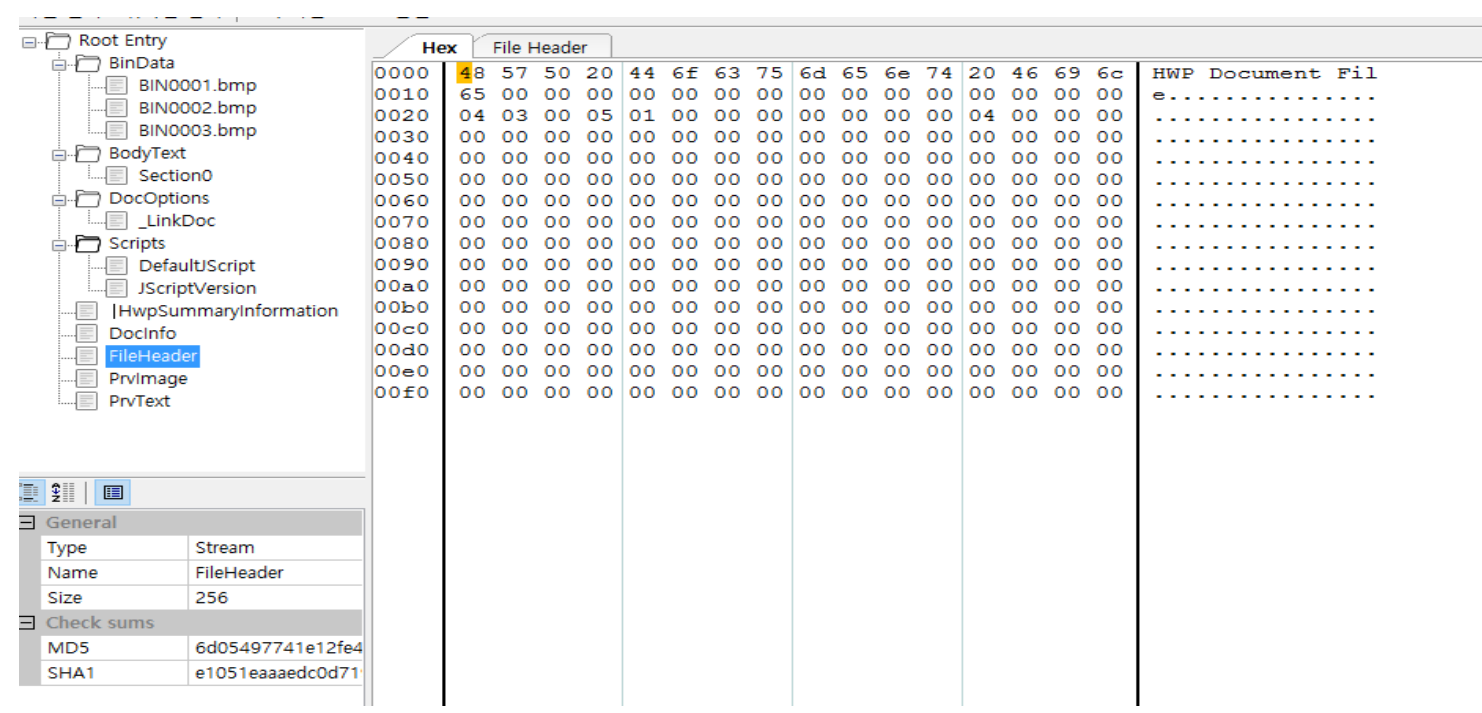

Figure 6. HWPSCAN2 execution screen 


\section{Design of Control System for Document Access}

We design the access control system using the structure information of "Hangul" document. First, we analyze the header information in the Hangul document. The header information of the Hangul document is as follows.

As shown in <Table 2>, access authority for a user is managed using specific header information through analysis of header information of Hangul document. In this paper, we use the information of the first 32 bytes +4 +4 positions in the header information of the Hangul document. Typically, this header is a header for managing information indicating whether or not compressed. Therefore, the header used in this paper uses information at a distance of 36 bytes from the header start position.

First, we describe the design contents for the access control system of Hangul document proposed in this paper.

\begin{tabular}{|c|c|c|c|}
\hline Type & Length (bytes) & \multicolumn{2}{|c|}{ Explanation } \\
\hline BYTE array[32] & 32 & \multicolumn{2}{|c|}{ signature. "HWP Document File" } \\
\hline DWORD & 4 & \multicolumn{2}{|c|}{$\begin{array}{l}\text { File version : 0xMMnnPPrr(ex)5.0.3.0) } \\
\text { - MM: The structure of the document format is completely changed. Different numbers } \\
\text { are not compatible with older versions. } \\
\text { • nn: Large structure is the same, but big changes. Different numbers are not } \\
\text { compatible with older versions. } \\
\text { - PP: The structure is the same, indicating that a record or information that is } \\
\text { incompatible with the lower version has been added. } \\
\text { - rr: Information is added to the record. }\end{array}$} \\
\hline \multirow{15}{*}{ DWORD } & \multirow{15}{*}{4} & \multicolumn{2}{|c|}{ property } \\
\hline & & range & Explanation \\
\hline & & bit 0 & compression \\
\hline & & bit 1 & password setting \\
\hline & & bit 2 & Documents for Distribution \\
\hline & & bit 3 & Script saving \\
\hline & & bit 4 & DRM security documents \\
\hline & & bit 5 & XML Template Storage Presence \\
\hline & & bit 6 & Presence of document history management \\
\hline & & bit 7 & existence of digital signature information \\
\hline & & bit 8 & Encrypting Certified Certificates \\
\hline & & bit 9 & Preservation of electronic signature \\
\hline & & bit 10 & Certified Certificate DRM Security Document \\
\hline & & bit 11 & CCL document \\
\hline & & bit $12 \sim 31$ & reservation \\
\hline BYTE array[216] & 216 & \multicolumn{2}{|l|}{ reservation } \\
\hline total length & 256 & & \\
\hline
\end{tabular}

Table 2. Hangul file header information

loc=lseek (fp , 36, SEEK_SET);
........
memset(\&buffer[0], 0xd8, 1);
memset(\&buffer[1], 0x00, 3);
........
write(fp, \&buffer[0],1);
.........

Figure 7. Permission to control the access to Hangul document 
First, it specifies the document file name for security access control. For the specified document, 36 offset position information in the Hangul document header information is set to a new value. It will write $0 x d 8000000$ to this location. By recording in this manner and setting it differently from the existing header information, the data existing in the Hangul file cannot be read. Then, the modified header information is overwritten with the original Hangul file.

Next is the process of releasing, that a user who has access rights to the Hangul document with the access authority control function dissolves the file. A user who has access rights uses the access control program which can dissolve Hangul file. The access control program is designed as follows.

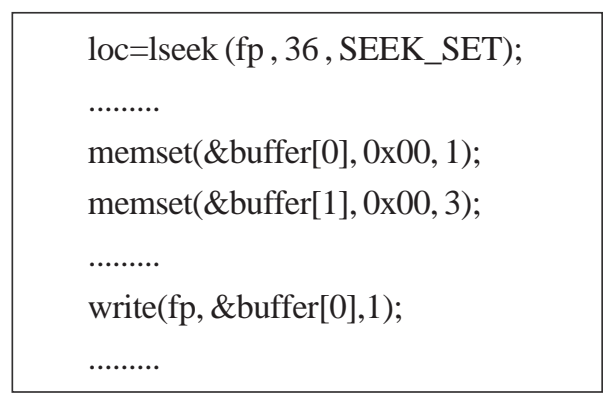

Figure 8. Release permission to control access to Hangul documents

\section{Experiment}

The environment for testing the implementation results of the proposed system in this paper is as follows. We use Microsoft Visual Studio 2012 as the programming language. Korean text editor uses Hancom Office Hangul 2010. In this paper, we test whether the proposed security access control system works correctly using the development and experimental environment.

First, we prepare a Hangul file for the experiment. The Hangul file is " $\mathrm{C} ;$ \ temp \1.hwp". The contents of this file are as follows.

It works the process that prevents access to the Hangul file except for the user who has access authority. The program that does this process is "auth_set.exe". This program is used to set the access right control function for the Hangul file,"auth_set.exe". When you open the file to view the contents of the Hangul file after setting it in the program, the screen is as shown in Figure 10 below.

In order to read this Hangul file normally, it is necessary to return the contents set as the access right through "auth_rel.exe" program to normal. The "auth_rel.exe" program will do that. The "auth_rel.exe" program will release access to the " $\mathrm{C} ; \backslash$ temp $\backslash 1$.hwp" file with the access control function enabled. When you release access control function with Auth_rel.exe "program, "C; $\backslash$ temp \1.hwp" file is read as Figure 11 as below.

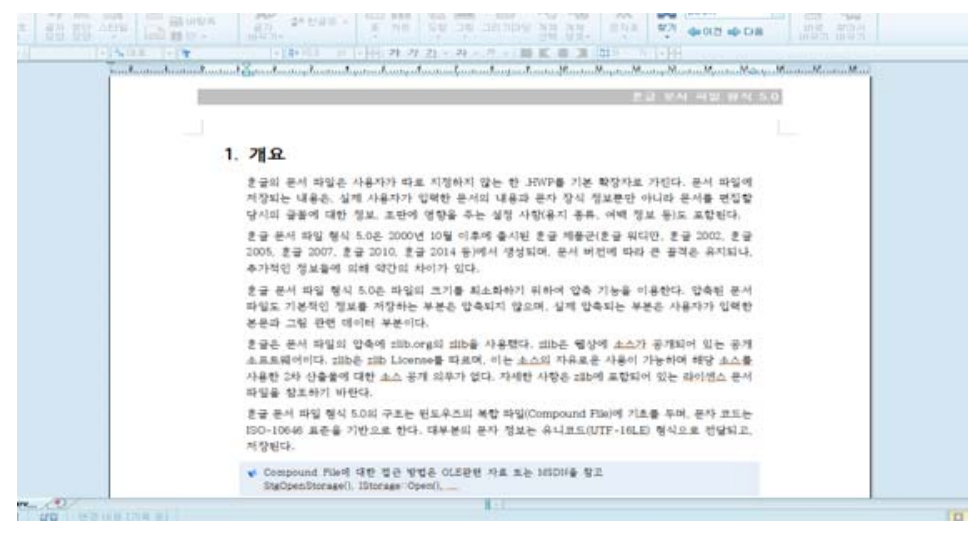

Figure 9. Hangul document without access authority

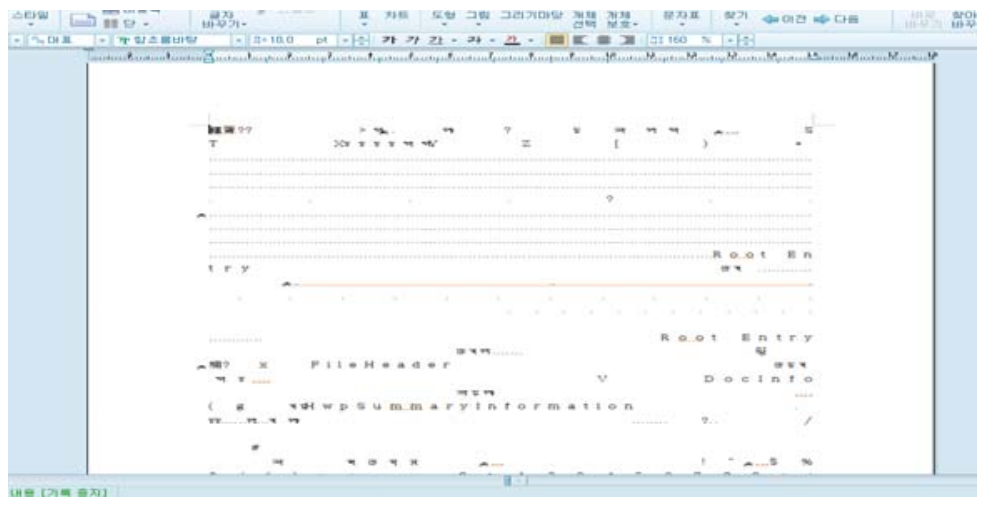

Figure 10. Secured Hangul documents 


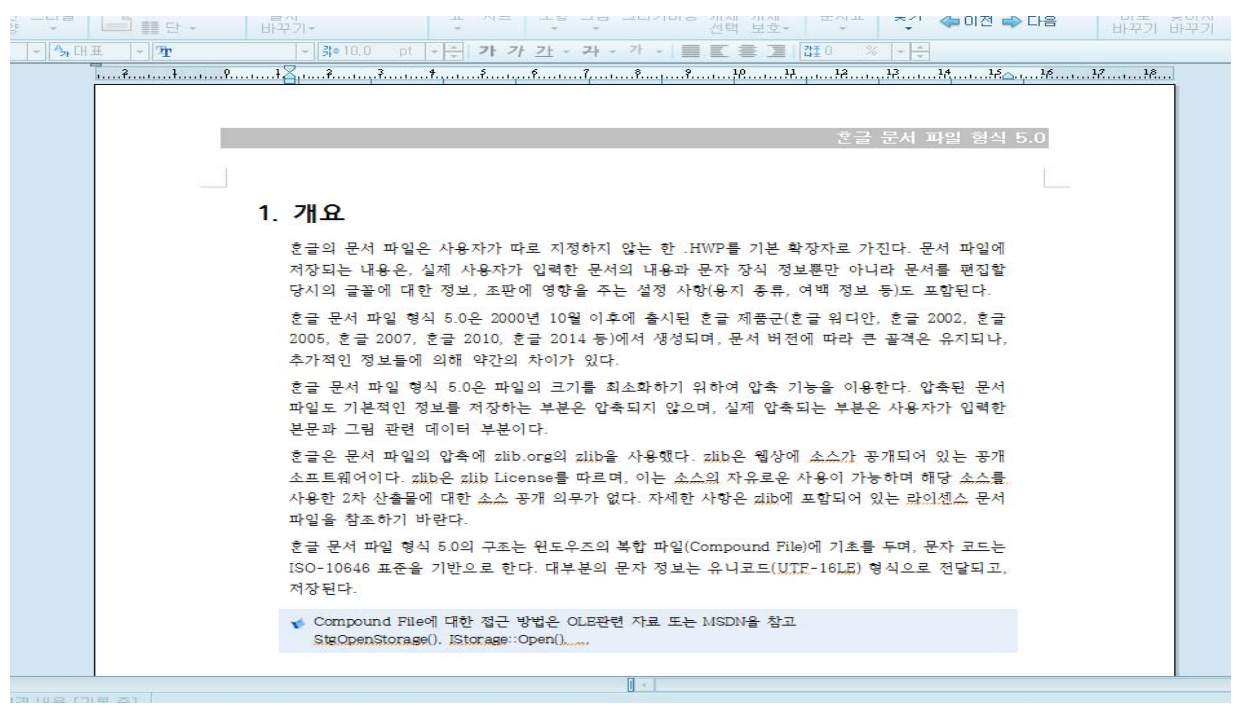

Figure 11. Hangul document after security release

As shown in the above experiment results, it shows that the Korean language file is reverted to the contents of the file before the control of security access authority. We have experimented the access control system of the Korean-language file proposed in this paper and we confirmed that the operation is normal.

In this paper, we have experimented on the designed contents. The results of the experiments are summarized in Table 2 below.

As shown in Table 2, we tested whether the design of access control function for Hanword document works properly in various aspects. The total number of experiments is 100 times. We experimented on Hangul file with ASCII data only, Hangul file with table, Hangul file with the equation, Hangul file with the picture, and Hangul file with all functions comprehensively. We confirmed that access control is normally performed for each case.

\section{Conclusion}

This paper designs a security system for Hangul file, which is the most used document system in Korea. In this paper, we design an access control system that a specific user with access rights can use Hangul document system. The system structure proposed in this paper analyzes the structure of Hangul document and modifies the head information of Hangul document. By securing the function of a specific field in Hangul document header information, a user who does not have data on the transformed information cannot open the document and view it.

In order to do this, we first analyze the structure of Hangul document system. In the analyzed Hangul document system, it decides what information to use to build the security system. In this paper, we design a control function of access right using the next 4 bytes of the file header information in the Hangul header system structure. This

\begin{tabular}{|c|c|c|c|c|c|}
\hline $\begin{array}{c}\text { Access Control Experiment } \\
\text { Number }\end{array}$ & ASCII Dataonly & IncludingTable & Including equation & Including Picture & All Kinds Document \\
\hline 100 & 20 & 20 & 20 & 20 & 20 \\
\hline Access Denied or not & Access Denied & Access Denied & Access Denied & Access Denied & Access Denied \\
\hline
\end{tabular}

Table 2. Experiment Results

allows you to control access to important Korean documents.

In this paper, we implemented the contents of design and conducted the experiments. The actual implemented system used the Visual Studio as the development environment. We performed experiments using the implemented system. Experiments were performed to see if normal Korean files were installed with security function first. Experimental results show that the general user cannot read the general Hangul file when the program implemented in this paper is executed. In the case of users who have access to Hangul file with security functions, we can confirm that the access control system works normally by using the access privilege using the program implemented in this paper.

\section{References}

[1] LG CNS, (2015). Electronic Document Security', You can do this. http://blog.Igcns.com/945.11.03.

[2] Park, Joong Oh., Lee, Seung Min., Kim, Sang Keun 
Chun, Mun Seok (2010). Implementation of Electronic Document Management System with Validation Period of Electronic Documents 35 (7)1043-1049.

[3] Hangul and Computer (2014). Text Document File Structure 5.0. 10 .

[4] Seong, Kyung Sang., Kim, Jung Jae., Oh, Hae Suk(2008). "System Design for the Safe store and Issue Service Assurance of the E-Document, Journal of the Korea Society of Computer and Information 13 (6)11, p.173-180.

[5] Kang, Bum II (2014). A Study on Classification of Financial Institutions Security Class, Korea University Master's Thesis, 2014.12

[6] Shin, Jae Ho., Kim, In Seok (2015). A Study on Personal Information Distribution Channel Detection based on Security Document and Transaction ID Linkage, Journal of The Korea Institute of Information Security, 25 (12)1435-1447, and p.1598-3978.
[7] Park, Min Gyu., Chung, Jung Yong., Kim , Yong Han., Park, Jae Hong (2015). Implementation of XML Conversion Software for PDF Documents.11, p.47-50.

[8] Park, Jung Soo., Ha, Jae Chul. (2012). Analysis of Vulnerability in Secure Document Management in Digital Multifunctional Devices and Their Solutions, Journal of Korean Institute of Information Technology 10 (6) 6, p.133143.

[9] Kim, Eun Kwang., Jeon., Sang Jun., Han, Jae Hyeok Lee., Min Wook, Lee., Sang, Jin. (2015). An effective detection method for hiding data in compound-document files, Journal of the Korea Institute of Information Security and Cryptology 25 (6)12, p.1485-1494.

[10] Hong, Seong Pyo., Lee, Cheol Seung. (2015). A Study on Verification of Validity Encrypted XML Documents, The journal of Korea Institute of Electronic Communication Sciences, 9 (2) 11, p.95-98. 